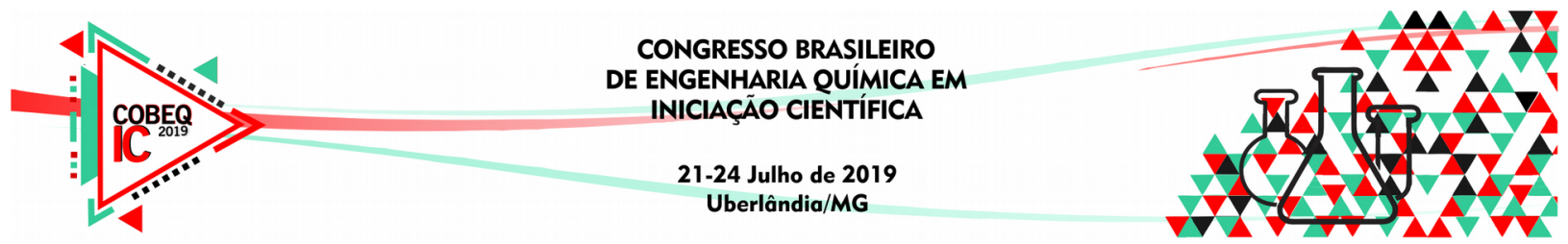

\title{
ESTUDO DA CINÉTICA DE SECAGEM DA PIMENTA ROSA POR CAST-TAPE DRYING
}

\author{
L. S. OLIVEIRA ${ }^{1}$, R. C. PICH ${ }^{1}$, R. C. SANTANA ${ }^{1}$ e M. F. ZOTARELLI ${ }^{1}$ \\ ${ }^{1}$ Universidade Federal de Uberlândia, Faculdade de Engenharia Química, Graduação em \\ Engenharia de Alimentos \\ E-mail para contato: raquelcp@unipam.edu.br; lorrane.oliveira@ufu.br; ricardocs@ufu.br; \\ martazotarelli@ufu.br
}

\begin{abstract}
RESUMO - A pimenta rosa é comumente utilizada como condimento gourmet. Além disso, tem propriedades antimicrobiana e antioxidante. Para um melhor aproveitamento desta matéria-prima é importante a aplicação de um método de preservação. Neste sentido, o cast-tape drying, utilizado na secagem de alimentos pastosos, é um método alternativo, relativamente recente e, por isso, ainda pouco investigado, apresentando potencial de produzir alimentos desidratados de alta qualidade. Este trabalho objetivou obter a cinética de secagem da pimenta rosa por cast-tape drying, para diferentes temperaturas da água de aquecimento, espessura da pasta espalhada e umidade inicial (consistência) da amostra.
\end{abstract}

\section{INTRODUÇÃO}

A pimenta rosa é um fruto utilizado, principalmente, como condimento gourmet, apresentando sabor adocicado e leve ardência. Tem sido empregada também, nas indústrias farmacêuticas e de cosméticos, pois apresenta propriedades medicinais, como atividade antioxidante e antimicrobiana (BERTOLDI, 2006).

Entretanto, a pimenta rosa ainda é subutilizada pela indústria, principalmente porque seus frutos são comercializados basicamente in natura ou em sua forma desidratada, a granel por métodos convencionais, sem uniformidade e controle adequado das condições do processo (ANDRADE, 2015). Neste sentido, a secagem da pimenta rosa por métodos não convencionais que busquem preservar suas características sensoriais, nutricionais e medicinais pode agregar valor a esta matéria-prima.

O cast-tape drying (CTD) é um método de secagem no qual o material a ser seco encontra-se na forma de uma pasta, sendo espalhado em um suporte plano polimérico que flutua sobre água aquecida. Tem sido usado para transformar frutas, legumes, ervas e outros produtos relacionados, em pós e concentrados de valor agregado, se mostrando atraente para aplicações na indústria de alimentos, pois os produtos secos são de alta qualidade, com preservação de compostos ativos aromáticos e pigmentos responsáveis pelas características sensoriais e nutricionais dos produtos (RAGHAVI et al., 2018).

Diante do que foi exposto e considerando a falta de informações na literatura a respeito da secagem de pimenta rosa por cast-tape drying, o objetivo deste trabalho foi estudar a cinética de secagem da pimenta rosa por pelo método de cast-tape drying. 


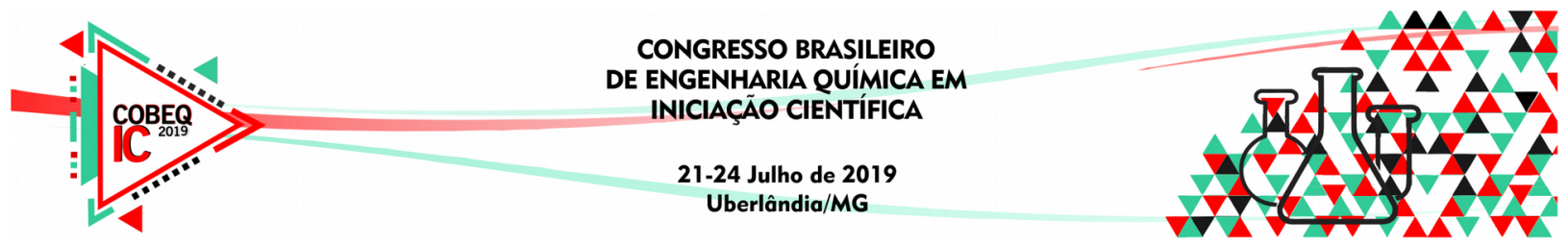

\section{MATERIAL E MÉTODOS}

\subsection{Preparação das Amostras}

Os frutos de pimenta rosa foram coletados de árvores nativas, no município de Patos de Minas - MG. Após a colheita, os frutos foram lavados (para retirada de sujidades), secos com o auxílio de papel toalha, e em seguida, colocados em embalagens poliméricas. Então, as amostras foram levadas a ultra-freezer (Indrel, modelo IULT335D, Brasil) a $-60^{\circ} \mathrm{C}$, permanecendo armazenados até a realização da secagem, sendo que, antes da desidratação, eram descongeladas durante $24 \mathrm{~h}$, em geladeira na temperatura entre 6 e $10^{\circ} \mathrm{C}$.

Para a obtenção de uma pasta com a consistência adequada para facilitar a aplicação e espalhamento uniforme sobre o suporte polimérico do secador, os frutos, após descongelamento, foram submetidos a uma operação de redução de tamanho, sendo triturados em multiprocessador. Na Figura 1 são mostradas fotografias dos frutos após a colheita e após sofrer redução de granulometria.

Figura 1 - Fotografias das amostras de pimenta rosa: a) após a colheita, b) triturada.

a)

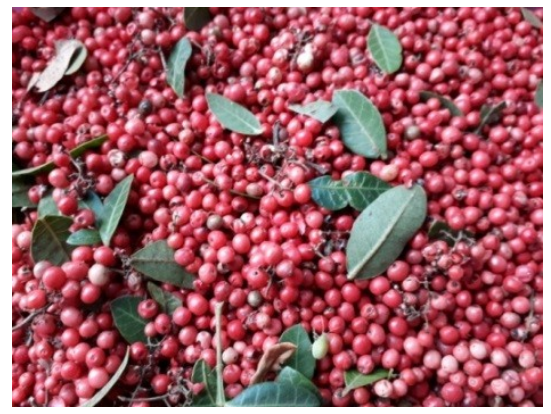

b)

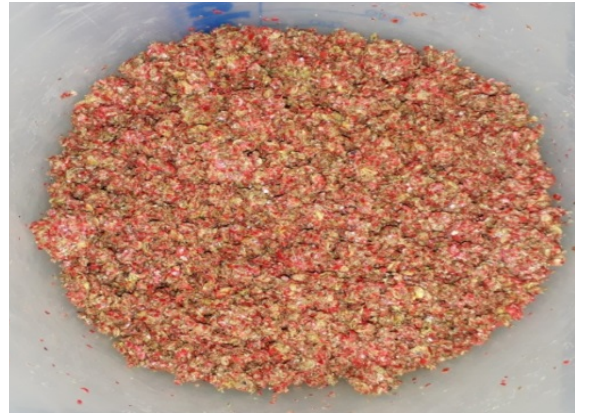

\subsection{Secagem por Cast-Tape Driyng}

Para a realização dos experimentos de secagem, o aparato experimental utilizado foi composto de um reservatório (bandeja de $0,7 \mathrm{~m} \times 0,3 \mathrm{~m} \times 0,05 \mathrm{~m}$ ) com água quente circulante, proveniente do um banho termostático (SOLAB, modelo SL 152/18, Brasil). Para a circulação da água foi utilizada uma bomba peristáltica (Cole-Parmer, modelo Masterflex L/S 77250-62, USA). O filme polimérico (mylar \&) (Dupont, USA) de 0,25 mm de espessura, foi fixado sobre o reservatório de forma que a face inferior ficasse em contato com a água quente circulante e a superior servisse de suporte para a pasta de pimenta rosa. Um esquema da unidade experimental de secagem utilizada é mostrado na Figura 2.

Figura 2 - Esquema da unidade experimental (ZOTARELLI et al., 2015 (adaptado)).

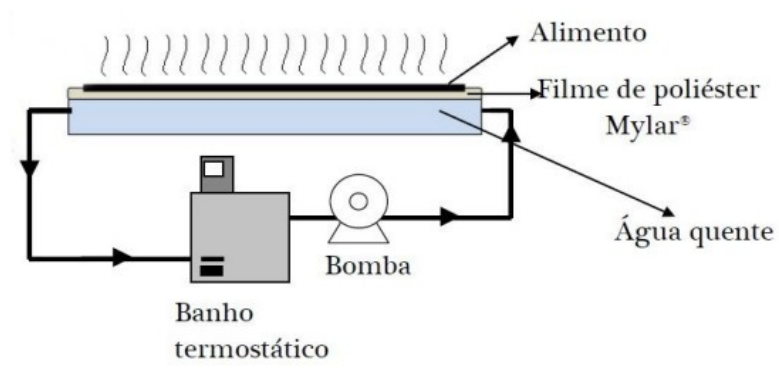




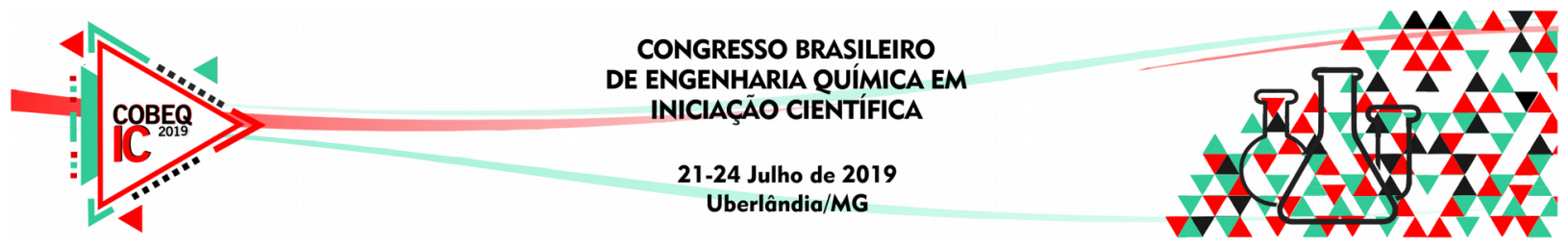

As condições experimentais avaliadas para o processo de secagem por cast-tape drying foram: espessura da camada da pasta de pimenta in natura espalhada sobre o filme do equipamento de 2 e $3 \mathrm{~mm}$; temperatura da água do banho termostático 65 , 75 e $95{ }^{\circ} \mathrm{C}$; e, quantidade de água adicionada à amostra de 0 e $40 \%$ de água, em relação à massa total de pimenta. Testou-se adição de água, visando obter uma pasta em condições mais satisfatórias de espalhamento que resultasse numa espessura uniforme da camada de pimenta. $O$ espalhamento sobre o filme polimérico $\left(\right.$ mylar $\left.^{\circledR}\right)$ foi realizado com auxílio de bastão tecnil, e utilizando molduras de acrílico de dimensões internas de $30 \mathrm{~cm}$ de comprimento e $15 \mathrm{~cm}$ de largura, espessuras de 2 e $3 \mathrm{~mm}$.

\subsection{Determinação da Cinética de Secagem}

A cinética de secagem foi realizada retirando amostras em triplicata, de posições distintas da camada de pimenta rosa na forma de pasta espalhada sobre o filme polimérico, durante intervalos de tempos pré-determinados. A umidade das amostras foi determinada segundo a metodologia A.O.A.C. (2005), sendo que o teor de umidade, em base seca, foi obtido conforme Equação 1, na qual $X_{t}$ é o teor de umidade da amostra, em base seca, (adimensional); $\mathrm{M}_{\mathrm{u}}$ é a massa da amostra úmida, em quilograma $(\mathrm{kg}) ; \mathrm{M}_{\mathrm{s}}$ é a massa da amostra seca em quilograma $(\mathrm{kg})$.

$$
X t=\frac{M u-M s}{M s}
$$

Na Figura 3 têm-se imagens da pimenta rosa triturada espalhada sobre o secador para a obtenção da cinética de secagem.

Figura 3 - Fotografias da amostra de pimenta rosa triturada espalhada sobre o secador.
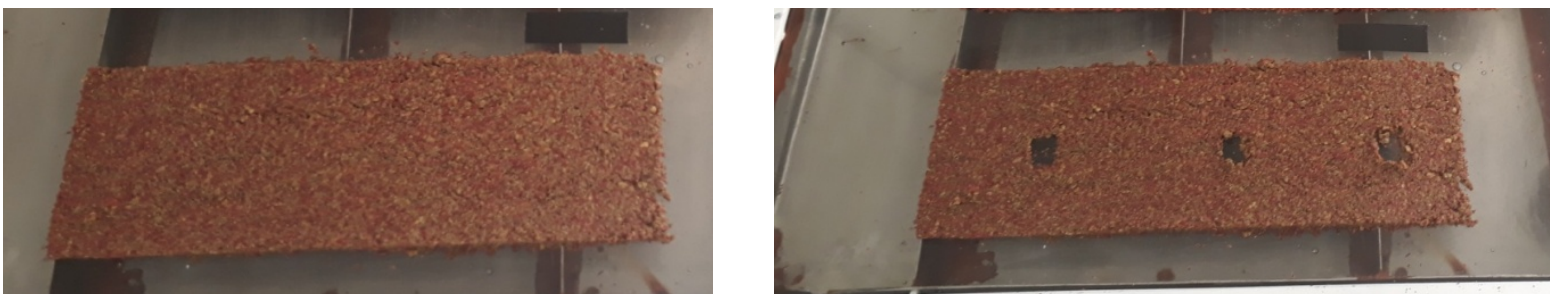

As taxas de secagem, no período de taxa constante, foram calculadas a partir da inclinação da equação da reta obtida na regressão linear realizada nos dados experimentais de umidade da pimenta em pasta em função do tempo de secagem.

\section{RESULTADOS E DISCUSSÕES}

A análise granulométrica da amostra seca foi determinada por peneiramento, utilizando um conjunto de peneiras padronizadas (série Tyler). Na Figura 4 é apresentada a distribuição de tamanho de partícula, mostrando que a redução de tamanho resultou uma amostra com granulometria heterogênea, em uma ampla faixa de tamanho. 


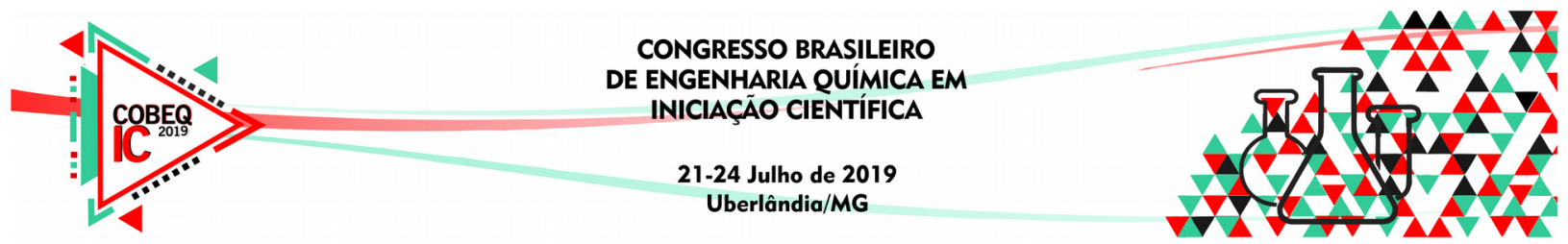

Figura 4 - Distribuição granulométrica da amostra de pimenta rosa seca.

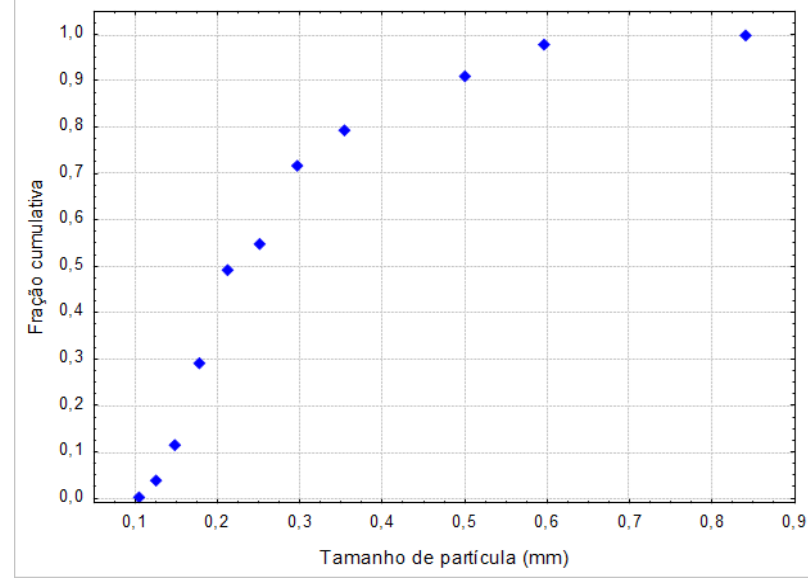

De acordo com a Equação 2, foi obtido o diâmetro médio de Sauter $\left(\mathrm{D}_{\mathrm{ps}}\right)$ das partículas, obtendo um valor de $0,0290 \mathrm{~mm}$. Nesta equação $\Delta \mathrm{x}_{\mathrm{i}}$ é a fração em massa retida em cada faixa e $\mathrm{D}_{\mathrm{i}}$ é o diâmetro médio em cada faixa da distribuição.

$$
D_{p s}=1 / \sum_{i} \frac{\Delta x_{i}}{\Delta D_{i}}
$$

No que diz respeito ao espalhamento, a adição de 40 \% (em peso) de água conduziu a uma pasta com consistência e escoabilidade operacionais mais satisfatórias durante $\mathrm{o}$ nivelamento da pasta na moldura de acrílico, proporcionando a obtenção de uma camada de pimenta com espessura mais uniforme. Neste sentido, adição de água nas amostras, embora leve a um material com maior teor de umidade a ser removida, é justificada pela melhora nas condições de espalhamento, o que permite um melhor controle do processo e pode resultar em um produto seco com características mais homogêneas. Em base seca, a amostra sem adição de água apresentava uma umidade de $0,522 \mathrm{~g}_{\text {água }} / \mathrm{g}_{\text {sólido seco }} \mathrm{e}$ a amostra com adição de $40 \%$ (em peso) de água uma umidade de $1,538 \mathrm{~g}_{\text {água }} / \mathrm{g}_{\text {sólido seco. }}$.

As curvas de secagem para a pasta dos frutos de pimenta rosa nas condições avaliadas estão apresentadas na Figura 5. Verificou-se que o aumento da temperatura da água circulante contribuiu de forma significativa para a redução do tempo de secagem, principalmente para a pasta de pimenta rosa sem adição de água com $2 \mathrm{~mm}$ de espessura, combinação mais favorável. Nesta condição, ao final do período de taxa de secagem constante, umidades menores que $0,12 \mathrm{~g}_{\text {água }} / \mathrm{g}_{\text {sólido seco }}$ foram alcançadas com 240, 210 e $40 \mathrm{~min}$, para as amostras secas a temperatura da água circulante de 65,75 e $95^{\circ} \mathrm{C}$, respectivamente. Já para as amostras com adição de $40 \%$ de água em peso e com espessura de espalhamento de $2 \mathrm{~mm}$, ao final do período de taxa de secagem constante, umidades menores que $0,12 \mathrm{~g}_{\text {água }} / \mathrm{g}_{\text {sólido seco foram }}$ alcançadas com 300, 300 e 90 min, para as amostras secas a temperatura da água circulante de 65,75 e $95{ }^{\circ} \mathrm{C}$, respectivamente. Estes resultados demonstram redução de mais de $80 \%$ no tempo de secagem quando a temperatura é elevada de 75 para $95{ }^{\circ} \mathrm{C}$ nas amostras espalhadas com $2 \mathrm{~mm}$ de espessura sem adição de água e uma redução de mais de $70 \%$ quando adicionou-se $40 \%$ de água. Estes resultados também podem ser verificados pelas taxas de secagem no período de taxa de secagem constante, conforme apresentado na Tabela 1. 


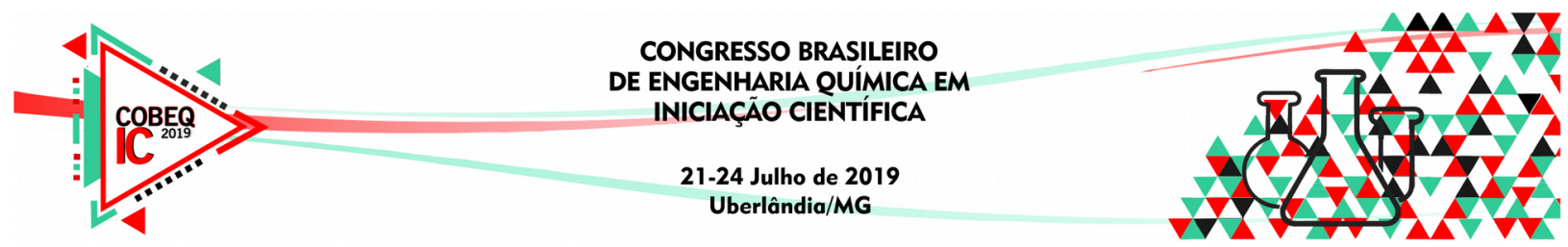

Figura 5 - Curvas de secagem dos frutos de pimenta rosas moídos.

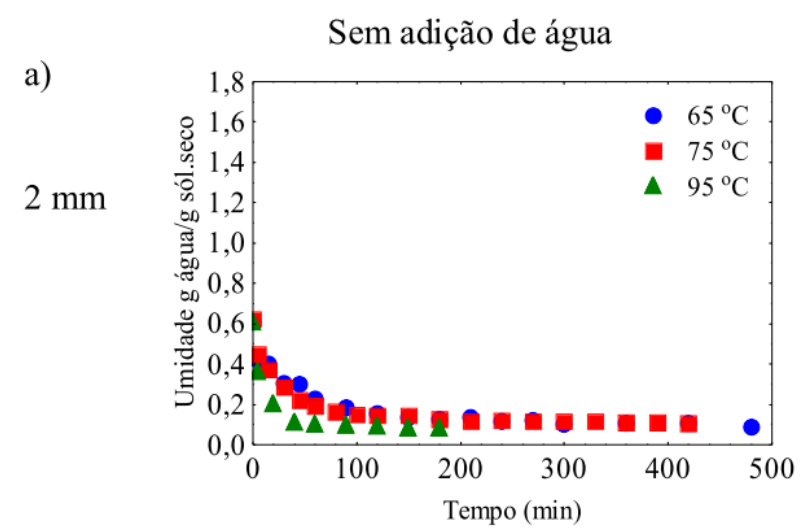

b)

Com adição de $40 \%$ de água
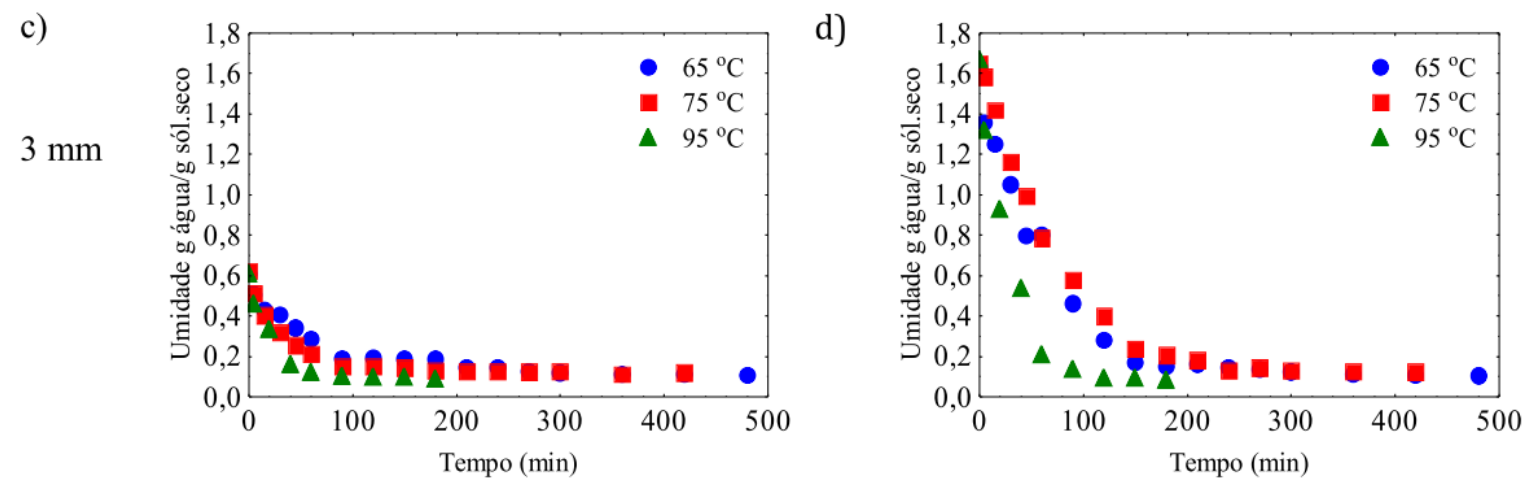

Tabela 1 - Taxa de secagem da pasta dos frutos de pimenta rosa

\begin{tabular}{|c|c|c|c|c|}
\hline $\begin{array}{l}\text { Temperatura da } \\
\text { água circulante } \\
\left({ }^{\circ} \mathrm{C}\right)\end{array}$ & $\begin{array}{c}\text { Espessura } \\
\text { da pasta } \\
(\mathrm{mm})\end{array}$ & $\begin{array}{c}\text { Quantidade de } \\
\text { água adicionada à } \\
\text { pasta (\%) }\end{array}$ & $\begin{array}{l}\text { Taxa de secagem } \\
\text { (ǵágua } / g_{\text {sól. seco.min })}\end{array}$ & $\mathrm{R}^{2}$ \\
\hline \multirow{4}{*}{65,0} & \multirow{2}{*}{2} & 0 & $0,0035 \pm 0,0004$ & 0,9544 \\
\hline & & 40 & $0,0124 \pm 0,0011$ & 0,9703 \\
\hline & \multirow{2}{*}{3} & 0 & $0,0035 \pm 0,0002$ & 0,9877 \\
\hline & & 40 & $0,0105 \pm 0,0009$ & 0,9691 \\
\hline \multirow{4}{*}{75,0} & \multirow{2}{*}{2} & 0 & $0,0047 \pm 0,0006$ & 0,9558 \\
\hline & & 40 & $0,0176 \pm 0,0023$ & 0,9528 \\
\hline & \multirow{2}{*}{3} & 0 & $0,0033 \pm 0,0004$ & 0,9470 \\
\hline & & 40 & $0,0119 \pm 0,0011$ & 0,9695 \\
\hline \multirow{4}{*}{95,0} & \multirow{2}{*}{2} & 0 & $0,0071 \pm 0,0017$ & 0,9431 \\
\hline & & 40 & $0,0190 \pm 0,0028$ & 0,9587 \\
\hline & \multirow{2}{*}{3} & 0 & $0,0063 \pm 0,0012$ & 0,9347 \\
\hline & & 40 & $0,0223 \pm 0,0027$ & 0,9601 \\
\hline
\end{tabular}

Para a pasta de pimenta rosa sem adição de água espalhada sobre o filme polimérico com $3 \mathrm{~mm}$ de espessura, verificou-se também que o aumento da temperatura da água circulante contribuiu de forma significativa para a redução do tempo de secagem. Nesta condição, ao final da taxa de secagem constante, umidades inferiores a $0,12 \mathrm{~g}_{\text {água }} / \mathrm{g}_{\text {sólido seco }}$ foram alcançadas com 300, 270 e 90 min para as amostras secas a temperatura da água 


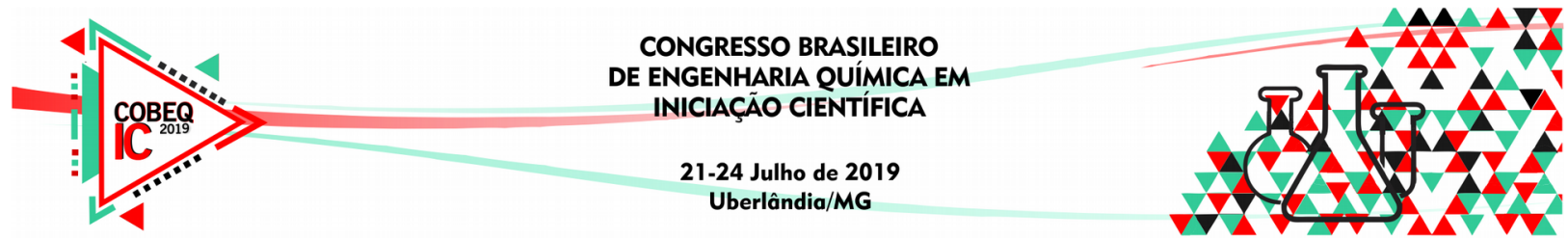

circulante de $65{ }^{\circ} \mathrm{C}, 75^{\circ} \mathrm{C}$ e $95{ }^{\circ} \mathrm{C}$, respectivamente. Já para a pasta com adição de $40 \%$ de água em peso e com $3 \mathrm{~mm}$ de espessura, ao final da taxa de secagem constante, umidades menores que $0,12 \mathrm{~g}_{\text {água }} / \mathrm{g}_{\text {śólido seco }}$ foram alcançadas com 360, 360 e $120 \mathrm{~min}$ para as amostras secas a temperatura de $65{ }^{\circ} \mathrm{C}, 75{ }^{\circ} \mathrm{C}$ e $95{ }^{\circ} \mathrm{C}$ respectivamente. Estes resultados demonstram redução de mais de $60 \%$ no tempo de secagem quando a temperatura é elevada de $75{ }^{\circ} \mathrm{C}$ para $95^{\circ} \mathrm{C}$ para as amostras espalhadas com $3 \mathrm{~mm}$ de espessura sem adição de água.

A maior diferença de temperatura entre a amostra e o ar próximo à superfície da amostra para as maiores temperaturas de secagem, resultou em maior transferência de calor, reduzindo o tempo de secagem. O tempo de secagem para a espessura de espalhamento de 2 $\mathrm{mm}$ foi menor porque o caminho para a migração de umidade desde o interior até a superfície, para então se transferir para o ambiente externo, também foi menor, (menor a resistência à transferência de massa). Também, têm-se uma maior quantidade de água a ser evaporada nas amostras adicionadas de $40 \%$ de água quando comparado às amostras sem adição de água.

A temperatura da água circulante, espessura da pasta e quantidade de água adicionada afetaram na taxa de secagem (Tabela 1), sendo que a temperatura teve maior efeito. De forma geral, para mesma temperatura e quantidade de água adicionada, aumentando a espessura da pasta de 2 para $3 \mathrm{~mm}$, as taxas reduziram entre 10 e $50 \%$ para as temperaturas entre $65^{\circ} \mathrm{C}$ e $95^{\circ} \mathrm{C}$, respectivamente, sendo as maiores reduções nas temperaturas mais elevadas.

\section{CONCLUSÃO}

Para que a pimenta rosa triturara atingisse consistência de pasta que permitisse o espalhamento foi necessária a adição de água. O equipamento experimental em batelada para secagem por cast-tape drying possibilitou estudar o processo de secagem da pimenta rosa moída e a influência da temperatura da água do banho termostático, da quantidade adicionada de água na amostra e da espessura da amostra na cinética de secagem. A temperatura da água e a espessura da camada de amostra influenciam significativamente na cinética de secagem por cast-tape drying. O tempo de secagem foi menor para a temperatura do banho termostático de $95^{\circ} \mathrm{C}$ e espessura da camada de amostra de $2 \mathrm{~mm}$ sem adição de água.

\section{REFERENCIAS}

ANDRADE, K. S. Extração e microencapsulamento de extratos de interesse biológicos provenientes de pimenta-do-reino (Piper nigrum L.) e de pimenta rosa (Schinus terebinthifolius R.). 164 f. Tese (Doutorado em Engenharia de Alimentos) - Universidade Federal de Santa Catarina, UFSC, Florianópolis, 2015.

BERTOLDI, M. C. Atividade antioxidante in vitro da fração fenólica, das oleorresinas e do óleo essencial de pimenta rosa (Schinus terebinthifolius Raddi). 116 f. Dissertação (Mestrado em Ciência e Tecnologia de Alimentos) - Universidade Federal de Viçosa, Viçosa, 2006.

RAGHAVI, L. M.; MOSES, J. A.; ANANDHARAMAKRISHNAN, C. Refractance window drying of foods: A review. Journal of Food Engineering, v. 222, p. 267-275, 2018.

ZOTARELLI, M. F.; CARCIOFI, B. A. M.; LAURINDO, J. B. Effect of process variables on the drying rate of mango pulp by Refractance Window. Food Research International, v. 69, p. 410-417, 2015. 